\title{
E-Portfolios and Exploring One's Identity in Teacher Education
}

Christine Ho Younghusband

School of Education

University of Northern British Columbia

\section{Correspondence:}

Christine Ho Younghusband

School of Education

University of Northern British Columbia

Email: christine.hoyounghusband [at] unbc.ca

Keywords: e-portfolio, professional identity, teacher education, practicum

\begin{abstract}
Academic faculty in a two-year post-baccalaureate teacher education program at a small research university in British Columbia explored the extended use of e-Portfolios into final practicum over a three-year period. The education technology course offered in Term Three asked teacher candidates to create and design an e-Portfolio as part of the coursework. In this program evaluation, the author investigated the continued use of ePortfolios into Term Four during final practicum. Faculty in this teacher education program sought ways to improve the program, particularly the practicum experience for teacher candidates. Extending the use of e-Portfolios into Term Four was one of three initiatives that were adopted. The e-Portfolio served as a digital platform for teacher candidates to archive, reflect, and sense-make; it also functioned as a means to develop their professional identities and understanding of the professional standards. The final practicum concluded with a Celebration of Learning and the capstone presentations referenced e-Portfolios. This paper focuses on how e-Portfolios were introduced and implemented with six cohorts, what was observed by the faculty member, and what was learned from the implementation to inform the future use of e-Portfolios in the program and program redesign. The extended use of ePortfolios during the final practicum was found to be a viable initiative and revealed professional qualities of teacher candidates that may not have been visible otherwise.
\end{abstract}




\section{Introduction}

\section{Background Information}

In 2018, a teacher education program (TEP) at a small research university in British Columbia $(\mathrm{BC})$ was at the cusp of educational reform with a vision to redesign the program and align to BC's Curriculum. The program redesign process started with finding ways to improve the final practicum experience for teacher candidates (TCs). One initiative involved extending the use of e-Portfolios into Term Four. This TEP is a two-year post-baccalaureate Bachelor of Education program that spans over four terms (with a summer term of non-instruction). In Term Three, TCs take the education technology course called EDUC 431, which includes creating and designing two websites, one for the classroom and the other as an e-Portfolio. TCs participate in a short practicum called EDUC 490 in Term Three, which lasts for four weeks; in it they teach approximately $50 \%$ of the time. In Term Four, the final practicum or EDUC 491 is 10 weeks long and TCs teach approximately $80-100 \%$ of the time. There is one secondary and one elementary cohort in this TEP. The focus of this program evaluation was to explore TC use of ePortfolios in Term Four during their final practicum with a focus on its viability, support for professional identity development, and application of the professional standards.

Three initiatives were implemented in 2018 to improve the practicum learning experience: triads, single point rubrics, and e-Portfolios. First, TCs were assigned into groups of three to form a peer-oriented triad intended to provide each other with ongoing support, formative feedback, and opportunities to collaborate or observe each other during practicum (Koehn \& Younghusband, 2019). Second, the single point rubric (Gonzalez, 2015) was used as a selfassessment tool for TCs and the Professional Standards for BC Educators (2019) as the criteria. TCs are evaluated against the professional standards during their practicum and the single point rubric gave TCs a framework to reflect, self-assess, and set goals. TCs could also share their rubrics with their teacher sponsor, practicum mentor, or triad members. Third, the program extended the use of e-Portfolios into Term Four during final practicum. For the ePortfolio, TCs are required to find artefacts that best reflect each professional standard (Kitchenham, 2008; Paul \& Scholefeld, 2009). Extending the use of e-Portfolios into Term Four allowed TCs to include artefacts from their final practicum and enabled them to reflect on their teaching and learning experiences as a digital narrative at the end of the TEP. The exploration of e-Portfolios spanned over three years, and is the focus of this program evaluation.

\section{Statement of the Problem}

EDUC 431 was taught in Term Three and artefacts collected for e-Portfolios were based on past experiences or coursework and practicum from Terms One, Two, and Three. However, TCs start to develop their teaching practice in Term Four during their final practicum because they are teaching at almost full capacity over an extended period. More specifically, they are deepening their understanding of the professional standards through practice, honing their teaching philosophy, and making connections between theory and practice (Stenberg et al., 2016). Artefacts from the final practicum were originally missed from the e-Portfolio. Extending the use of e-Portfolios into Term Four shifted the learning intention from creation and design using education technology to using the e-Portfolio as a digital platform to explore one's professional identity and the professional standards. 


\section{Guiding Question}

In what ways does extending the use of e-Portfolios into Term 4 enhance the practicum experience and one's expression of professional identity through the lens of the professional standards?

\section{Purpose of the Program Evaluation}

The purpose of this program evaluation was to explore the use of e-Portfolios during final practicum over a three-year period and gain insights to inform the program redesign committee on the future use of e-Portfolios in the TEP. The Professional Standards for BC Educators (2019) and aspects of BC's Curriculum (2021) remain central to the e-Portfolio and its contents. The final practicum concludes with a Celebration of Learning, where TCs would gather back on campus to present a capstone presentation on one or two big ideas learned from practicum and the program. The contents of the e-Portfolio and the final practicum learning experience provided content to the capstone presentation. The program evaluation, which drew upon processes often used in action research, sought to determine if extending the use of e-Portfolios into final practicum was viable and if e-Portfolios helped deepen one's understanding of the professional standards to develop of one's professional identity as a teacher.

\section{Information about the Faculty Member}

The faculty member is the author of this paper and implemented this program evaluation. They teach full-time at the university and joined the TEP in 2018. They have a background in $\mathrm{K}-12$ education in BC public schools, completed a doctorate degree in leadership, use WordPress as a professional blog, and teach the practicum courses in Term Three and Term Four. The faculty member is currently the B.Ed. Coordinator of the TEP, a member of the B.Ed. program redesign committee, and the academic lead of the e-Portfolio initiative. They have some experience in education technology using WordPress and Twitter. The program underwent many changes in faculty, leadership, and support staff when the faculty member joined the TEP a few years ago. As a new faculty member, they wanted to participate in the program evaluation process, find ways to improve the practicum experience and align the TEP to BC's Curriculum.

\section{Conceptual Framework}

Reflection is an integral part of the learning process. Drawing upon Kolb's (1984) experiential learning cycle, TCs start with a concrete experience, reflect on that experience, and learn from that experience; then they hypothesize what they could do differently and try again. According to Schön (1983), professionals reflect in action and reflect on action. Reflecting in action is learning by doing. TCs learn how to teach as they are teaching. Reflecting on action is looking back at an experience and evaluating what went well and what could have been different. Both experiential learning and reflecting on action (and in action) relate to e-Portfolios as Assessment as Learning where TCs are thinking about their thinking (Earl, 2003). Through a reflective practice, it is expected that TCs can develop their metacognitive skills by reflecting on action using e-Portfolios, but also by reflecting in action as they curate their digital narrative. TCs are expected to use e-Portfolios to reflect, monitor, and self-assess their teaching performance based on the professional standards. 
Assessment as learning involves self-monitoring and adjusting to make sense of information, connecting to prior knowledge, and acquiring new knowledge (Crown in Right of Manitoba, 2006; Earl, 2003). It is expected that TCs can self-assess, critically reflect, and think about their thinking so that over time they become their best assessors (Crown in Right of Manitoba, 2006; Earl, 2003; Rowe, 2012) using e-Portfolios. This form of formative assessment extends the role of TCs. They can make connections to their contributions to assessment and the learning process, while they continue to reflect on their work and make judgements (Earl, 2003). Assessment as learning engages and empowers the learner (Earl, 2003). TCs can use personal knowledge to construct meaning (Earl, 2003) and e-Portfolios can help TCs to monitor, reflect, self-assess, sense-make, adjust, and choose artefacts that reflect who they are as teachers and learners.

\section{Literature Review}

\section{BC's Curriculum and Professional Standards}

In 2016, leaders in K-12 education in British Columbia (BC) embarked on a transformative curriculum change with BC's New Curriculum. The curriculum was implemented for all subject areas and grade levels from K-9 in 2016, and incrementally for grades 10-12 over the next few years. The "know-do-understand" curriculum framework focused on a concept-based, personalized, competency-driven learning experience (Province of British Columbia, 2021) to develop The Educated Citizen as described in the Statement of Education Policy Order (1989). The curriculum encourages a student-centred approach that provides flexibility and choice, focuses on numeracy and literacy, and integrates Indigenous knowledges and perspectives (Province of British Columbia, 2021) as well as First Peoples Principles of Learning (First Nations Education Steering Committee [FNESC], 2008).

The Learning Standards, or content and curricular competencies, are assessed and evaluated by the teacher and reported out by Communicating Student Learning (CSL) or formal reporting periods (Province of British Columbia, 2021). The expectation is that by knowing the content and doing the curricular competencies, student start to understand the Big Ideas, or enduring understandings. Every learning experience is intended to contribute to BC's Curriculum Core Competencies (i.e., thinking, communicating, and personal/social); where students self-assess personal growth over time (Province of British Columbia, 2021). Students are expected to develop ownership of their learning through a reflective practice and development of metacognitive skills and summarize their learning with a year-end self-assessment or capstone project in grade 12 (Province of British Columbia, 2021). For TCs, they can use e-Portfolios for ongoing reflection and self-assessment, and documentation of their competencies as teachers.

The Professional Standards for BC Educators (2019) guide teacher education programs (TEPs), but also set the criteria for teacher candidates (TCs) to be assessed and evaluated by during final their practicum. The professional standards are to be embedded in all courses in the TEP and used to advance the work of K-12 educators and TCs in BC because they "communicate the knowledge, skills, attitudes and values that define educators' work" (BC Teachers' Council [BCTC], 2019, p. 2). The professional standards also focus on working "towards truth, reconciliation, and healing" (BCTC, 2019, p. 2) and aligning to the Truth and Reconciliation Commission of Canada's Calls to Action (2015) 62 and 63, as well as following the First Peoples Principles of Learning (2018), and BC's Curriculum (2021). The newest Professional 
Standard for BC Educators (2019), Standard 9, states that

Educators critically examine their own biases, attitudes, beliefs, values and practices to facilitate change. Educators [to] value and respect the languages, heritages, cultures, and ways of knowing and being of First Nations, Inuit and Métis. Educators understand the power of focusing on connectedness and relationships to oneself, family, community and the natural world. Educators [are to] integrate First Nations, Inuit and Métis worldviews and perspectives into learning environments. (p. 5)

It is expected that TCs benefit from the time and space in the TEP to unpack and examine Standard 9 and their values, beliefs, and personal biases, but also to self-assess and reflect on their understandings of history and community through coursework, practicum, and past experiences. By contributing to an e-Portfolio during final practicum, for example, there is a potential for TCs to develop the Core Competencies, participate in digital storytelling and develop one's identity, in addition to monitor and self-assess their growth over time as a curated digital narrative of their professional identity.

\section{E-Portfolios}

e-Portfolios are used by TEPs to help TCs to critically reflect, document, and make meaning of the practicum experience and connect theory to practice (Maharsi, 2019). Uses vary from being process oriented, formative, and reflective as learning portfolios, to accountability portfolios to evaluate TCs, to marketing portfolios to showcase to future employers (Granberg, 2010). In this TEP, e-Portfolios were used for all three purposes. However, this program evaluation focused on e-Portfolios as a self-assessment tool and digital receptacle for artefacts that co-relate to the professional standards (Kitchenham, 2008; Paul \& Scholefield, 2009). The e-Portfolio served as a vehicle for reflection, content creation, self-assessment, and celebration (Granberg, 2010).

At this university, TCs created and designed e-Portfolios for the education technology course, found artefacts, and wrote a 300-800-word rationale to describe how they were co-related to the professional standards (Kitchenham, 2008). In another BC TEP, TCs participated in ePortfolios as part of their program and worked with faculty complete the assignment using WordPress (Paul \& Scholefield, 2009). TCs found this platform frustrating to use at times for formatting and personalizing, but overall, they enjoyed the assignment, it was good for selfreflection after completing practicum, and recommended projects to track professional growth (Paul \& Scholefield, 2009). Furthermore, "portfolios provide a space where pre-service teachers can reflect 'on' and 'in' practice by making links between evidence in their e-Portfolio and the development of their professional identity" (Schön, 1983, cited in Boulton, 2014, p. 376). Identity is important to learning because it connects people to others and the community and helps one to understand their place, their strengths and challenges, ways to contribute, and feelings of belonging (Chrona, 2014). Indeed, "learning requires the exploration of one's identity" (FNESC, 2008). TCs can use e-Portfolios to explore their values, beliefs, and professional identity as a teacher.

\section{Professional Identity}

TCs transform over time within the TEP from the identity of student to learner/educator. At first, TCs display studenting behaviours that do not contribute to learning but rather to gaming behaviours (Liljedahl \& Allen, 2013). For example, the focus is more about the grade and how to 
get the grade rather understanding what is being taught and why it matters. They are driven by the goods external to the practice (i.e., grades, competition) instead of the goods internal to the practice (i.e., curiosity, wholeheartedness; Maclntyre, 1981). e-Portfolios can help develop a reflective practice, link theory to practice, and identity personal goals (Boulton, 2014). In addition, "the use of reflective activities in teacher education programmes bring about positive changes in the [TC's] self-knowledge, cognitive and emotional selves, sense of agency, voice, confidence as a teacher and self-dependency" (Izadinia, 2013, p. 700). Taking the time to connect self-reflection to self-identity is worthwhile in TEPs (Boulton, 2014). You teach who you are (Palmer, 1989). Understanding one's identity can help one to understand their experiences, gain awareness of their surroundings, and recognize their values, gifts, and areas for growth (Chrona, 2014).

TCs need explicit time for sense-making, to write and rewrite their narrative, and reflect on their values and beliefs (Eliot \& Turns, 2011). Exploring and developing one's professional identity in teacher education aligns to the Core Competencies of BC's Curriculum (Province of British Columbia, 2021) and what it means to be a teacher. Teachers are learners (Stolz, 2020). TCs can discover their professional identity by first looking at past experiences, pre-conceptions of teaching, and self-knowledge (Friesen \& Besley, 2013). "Learning is embedded in memory, history and story" (FNESC, 2008), and our identities are always changing (Palmer, 1984). Our identity influences what we teach, the decisions we make, and the relationships we create with students (Izadinia, 2013). TCs using e-Portfolios to discover who they are as educators and learners can be part of the process of developing their sense of purpose and educational philosophy. What's more, "those individuals who had explored their values and beliefs and had developed a greater sense of self-knowledge [are] better positioned to consider the values and roles of the teaching profession" (Friesen \& Besley, 2013, p. 24). TCs need to deeply understand the professional standards, who they are as educators, and what's expected of them in the profession.

\section{Overview of Program Evaluation}

This is a program evaluation that drew upon processes often used in action research. The faculty member who led the initiative to extend the use of e-Portfolios into final practicum is the author of this paper. Much like action research, this program evaluation was conducted by someone within the learning community to pursue a better understanding of a given situation through inquiry and outcomes from the implementation lead to an action plan (Hinchey, 2008). The process is cyclic, reflective, and seeks to improve practice (or program) through a method of inquiry where knowledge is socially constructed, there is no single truth, and findings may be helpful to others in related situations (Hinchey, 2008). The outcomes are not universal.

The framework used to guide this program evaluation of extending the use of e-Portfolios was the Spirals of Inquiry (Kaiser \& Halbert, 2017) which has six phases: scan, focus, develop a hunch, learn, take-action, and check. The scan involved noticing that TCs were not taking ownership of their final practicum experience and being the agents of their learning during practicum. The focus was to find ways in which TCs could self-assess their teaching and learning during practicum in a meaningful and purposeful way. The hunch was comprised of three parts. First, was an understanding that the e-Portfolios were taught, learned, and completed in Term Three during EDUC 431 with a focus on education technology. Second was that they were not used in Term Four during final practicum. Finally, TCs blogs were not included in the e-Portfolio as a reflective tool for sense-making. The learn phase determined if 
TCs could maintain e-Portfolios during final practicum and if they helped TCs develop their professional identity. The take-action phase involved introducing TCs to e-Portfolios in Term Three, discussions about continuing the use of e-Portfolios during the final practicum, and direction on how to include artefacts and reflections from Term Four to create a digital narrative of their professional identity. The check involved e-Portfolio completion, the Celebration of Learning, Twitter posts, observations made by the faculty member, and notes of context and noteworthy events over a three-year period. The outcomes of the program evaluation informed next steps and future use of e-Portfolios.

At this small research university in British Columbia (BC), there are two cohorts per annual intake in the teacher education program (TEP): the secondary years (SY) and elementary years (EY). The implementation of the e-Portfolio initiative spanned over six cohorts (approximately 10-30 students each) over three years, from 2018 to 2020.

\section{Implementation of e-Portfolio Initiative}

The expectation of completing an e-Portfolio during EDUC 491 (the 10-week final practicum) was made evident in the course syllabus. Over three years, each set of EY and SY cohorts were introduced to the e-Portfolio initiative differently, depending on who taught EDUC 431 (the Education Technology course) or EDUC 490 (four-week practicum course) in Term Three of the TEP. Different people taught EDUC 431 over the three years (i.e., the faculty member taught EDUC 431 to both cohorts in 2019 but did not teach EDUC 431 in 2018 or 2020). However, the faculty member taught EDUC 490 to some of the cohorts over the three years and taught all six cohorts for EDUC 491 (final practicum course) in Term Four. As a result, extending the use of ePortfolios from Term Three into Term Four was introduced in either EDUC 490 or EDUC 431.

The 2018 cohorts were encouraged to add additional artefacts, reflections, or exemplars from final practicum onto their Wix.com or Weebly.com site. The 2019 and 2020 cohorts did not create their e-Portfolio website; instead, they were provided an e-Portfolio template made on an open-sourced WordPress site from OpenETC (see Figure 1). Using OpenETC was desirable because it was free to use, FIPPA compliant, included extra plug-ins and template designs, and the university technology expert was a member of OpenETC who provided technical support during implementation. Much like the 2018 cohorts, the template included an About Me page and the BC Teacher Standards. The template also included a Portfolio Components tab, a Practicum Experience tab, and a blog as the landing page. Each tab allowed for additional subpages for TCs to personalize and highlight work experiences, values and beliefs, and exemplars of their Assessment for Learning, First Peoples Principles of Learning, and inclusive practices.

The 2020 cohorts were not required to make an e-Portfolio during EDUC 431. As a result, these cohorts did not draw upon the same education technology skills set as the previous cohorts. Cohorts were exposed to WordPress and web design experientially. All cohorts in the implementation were encouraged to use Twitter as a microblog and embed the feed into their ePortfolios. However, Twitter use was not required due to personal choice, comfort with social media, and one's digital footprint. Final practicum concluded with a Celebration of Learning and capstone presentation. TCs prepared a short presentation on the big ideas learned during practicum and program and used their e-Portfolios for content. TCs presented to first year TCs, faculty, and school district staff. The 2018 cohorts presented individually in a four-minute Ignite

Open/Technology in Education, Society, and Scholarship Association Journal: 2021, Vol. 1(2) 1-17 


\section{Figure 1}

Screenshot of Landing Page of E-Portfolio Template

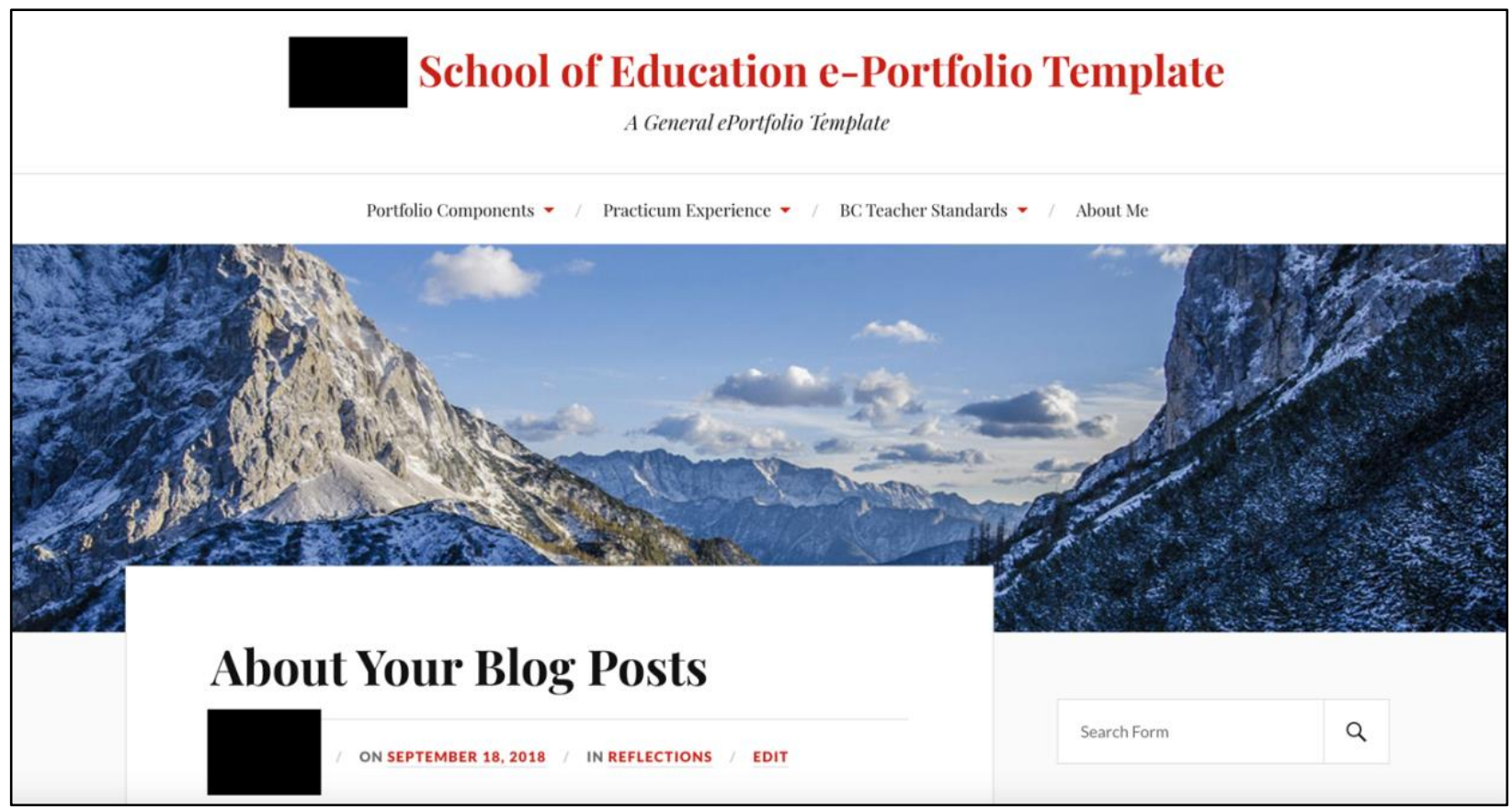

presentation, the 2019 cohorts submitted triad presentations and scripts electronically, and the 2020 cohorts presented online for 10 minutes with their triad. Individual and triad presentations self-identified big ideas to share with the audience that were important for them to learn during practicum.

\section{Collection of Program Information}

Program information was collected from the Celebration of Learning, observations made by the faculty member, Twitter posts, completed e-Portfolios, and notes taken by the faculty member during the three years of implementing the extension of e-Portfolio use during final practicum. Cohorts presented their learning differently each year at the Celebration of Learning due to unforeseen events and program delivery determined by the pandemic and COVID-19 safety protocols. Some presentations were in person, in triads, online, or completed asynchronously.

The information collected over the three years was used to determine the viability of e-Portfolio use during final practicum and to better understand the ways e-Portfolios can help TCs develop their professional identity and deepen their understanding of the professional standards. What was observed by the faculty member during the e-Portfolio implementation was context, content, and contribution.

\section{Key Themes}

Three themes were identified from the extended use of e-Portfolios during final practicum as Teacher Candidates (TCs) developed their professional identity as teachers: (a) overcoming obstacles (i.e., context), (b) getting the big ideas (i.e., content), and the (c) willingness to share 
(i.e., contribution). During the initiative, all e-Portfolios were maintained and completed in Term Four and met program expectations, and all TCs participated in the Celebration of Learning.

\section{Overcoming Obstacles}

The first theme identified was the context in which the implementation took place each year. Over the three-year period, cohorts overcame unique challenges within the university and program that were not typical circumstances for the teacher education program (TEP). These obstacles were extraordinary and implementing a new initiative like e-Portfolios during final practicum would have been met with some resistance and refusal. Despite unprecedented events, TCs were able to follow through, demonstrate qualities of resilience, persistence, and grit, and complete the e-Portfolio by the end of practicum to participate in the Celebration of Learning. The next few sections describe the context of the learning environment during implementation.

\section{Changing Faculty, Changing Expectations}

The 2018 cohorts experienced significant changes in faculty, staff, and leadership mid-program, which resulted in changed expectations and varied levels of uncertainty and angst. The University was also changing its structure from two colleges to five faculties, several faculty members left or retired from the department, and leadership and support staff were in a state of flux with a new interim dean and temporary administrative staff. New faculty, new staff, and new leadership within the department had the effect of disrupting program expectations of the TEP. As result of this context, TCs in general expressed the desire to finish the program as soon as possible and move into K-12 teaching positions.

The 2018 cohorts initially pushed back at the idea of continuing e-Portfolios after Term Three. As an aggregate group, the 2018 cohort believed they met the course criteria for EDUC 431 and did not embrace the purpose of extending its use into Term Four. Although the learning intention for e-Portfolios would be different for final practicum, the initiative was perceived to be "add on" or additional work. In this first cycle, the 2018 cohort was encouraged to add new artefacts from final practicum into their e-Portfolio. Although informal feedback after the program ended indicated some overall group awareness of the benefit of the e-Portfolio as a tool for reflection, in general the 2018 cohort made little or no changes to their e-Portfolio in Term Four after completing it in Term Three. However, the 2018 cohorts met program expectations, submitted e-Portfolios, and presented a four-minute Ignite presentation using their e-Portfolio to highlight their learning.

\section{Faculty Strike and the Pandemic}

The 2019 cohorts experienced a faculty strike in Term Three and pivoted to remote learning in Term Four due to the COVID-19 pandemic and school closures in K-12. In both situations, approximately three weeks of instructional and practicum time were lost due to these unexpected interruptions. TCs started working on their e-Portfolios in EDUC 431 using WordPress and the template and were able to continue its use during final practicum. Because the introduction of the e-Portfolio and expectations of extended use were set during EDUC 431, the transition to e-Portfolios during final practicum was seamless despite the labour dispute and strike. The cohorts applied their EdTech knowledge to their e-Portfolio by incorporating applications like YouTube, Sketchnote, vlogs, audio recordings, photo collages, and Twitter. The 2019 cohorts used FIPPA compliant images, uploaded lesson plans, and blogged. Initially,

Open/Technology in Education, Society, and Scholarship Association Journal: 2021, Vol. 1(2) 1-17 
the 2019 cohorts expressed uncertainty about blogging, but over time they demonstrated the formative nature of e-Portfolios and use beyond showcasing achievements, earning a final grade, or getting a job interview. The blog was formative, and webpages were summative. Overall, artefacts chosen by TCs to represent the professional standards were intentional and the blog posts were reflective.

The final practicum ended early due to the pandemic and $\mathrm{K}-12$ school closures. Although time was not spent teaching in the classroom for practicum, TCs used this time to complete their ePortfolios and submit them at the end of the term. The TCs collaborated with their triad online to co-create their capstone presentation. The Celebration of Learning was cancelled due to the uncertainty of the pandemic. Triads submitted their presentations electronically by email with a written script as the adaptation for not presenting in person or synchronously online. All triad presentations were submitted and TCs were able to complete and maintain e-Portfolios.

\section{Remote Learning and No Prep}

The 2020 cohorts completed coursework online due to remote learning and COVID-19. K-12 schools reopened, and practicum resumed as planned with COVID-19 safety protocols in place. TCs were not required to create an e-Portfolio in EDUC 431, therefore these TCs were introduced to e-Portfolios during their 4-week practicum course, EDUC 490, in Term Three and continued their use in Term Four during final practicum. TCs used WordPress and the template and spent asynchronous course hours learning how to use the platform to experiment with web design and personalize their e-Portfolio. The formative and summative aspects of the e-Portfolio were emphasized as well as what was expected in the program by the end of Term Four.

In triads, TCs presented their capstone presentations online via Zoom to new TCs, faculty, and school district staff. All e-Portfolios were completed and submitted at the end of final practicum. Although the 2020 cohorts did not have opportunity to develop the same education technology background as cohorts in previous years, the TCs were equally committed to contributing to their e-Portfolios. The TCs added items from coursework, such as their Pedagogical Stance from the Foundations of Education course, and content within their e-Portfolios generally focused on their teaching and learning experiences within the TEP, with exception to the About Me page and any personalized pages highlighting values and beliefs, work experiences, or interests. A couple of TCs created additional webpages to communicate with parents and students during final practicum. The 2020 cohorts were able to use the e-Portfolio during final practicum despite their varied experience in EDUC 431.

\section{Summary}

Regardless of exceptional and unpreceded circumstances during each year of implementation, TCs were able to maintain and complete an e-Portfolio during final practicum and include different applications, coursework, and additional pages to personalize their e-Portfolio. The potential of extending the use of e-Portfolios into final practicum and collaborating with other courses such as EDUC 431 and EDUC 490 under ordinary circumstances is unimaginable. The outcomes of the implementation would be potentially better and collaboration or integration with other courses would add more coherence to the program, practicum, and initiative. 


\section{Getting the Big Ideas}

The second theme identified from using e-Portfolios during final practicum was getting the big ideas (or content) of the TEP (see Table 1) as presented during the Celebration of Learning. In 2018, the big ideas were collectively identified by the cohort of first year TCs who witnessed the capstone presentations and made note of the big ideas they heard from each presentation. A summary of these big ideas is listed in Table 1. In 2019 and 2020, the big ideas listed were selfidentified by each triad, which were informed by their final practicum experiences and ePortfolios.

\section{Table 1}

List of big ideas shared during the Celebration of Learning

\begin{tabular}{ccc}
\hline 2018 Cohorts $^{1}$ & 2019 Cohorts $^{2}$ & 2020 Cohorts $^{3}$ \\
\hline Be authentic & Building relationships & Holistic education \\
Differentiate & Engaging activities & Experiential learning \\
Make learning accessible & Relationships & Student engagement \\
It's ok to be yourself & ADST & Outdoor education \\
Peers help to reduce stress & Diversity & Building relationships \\
Self-care matters & Flexibility & Teacher wellness \\
Build relationships & Motivation & \\
Embrace who I am & Purposeful play & \\
Take advantage of your triad & Leadership & \\
Meet every student's needs & Relevance and engagement & \\
Be organized & Experiential learning & \\
Use your strengths & Authenticity & \\
More inquiry projects & Differentiation & \\
Different students need & Reflective and reflexive & \\
different strategies & teaching & \\
\hline
\end{tabular}

Note: There are two cohorts per annual intake: elementary years and secondary years.

${ }^{1}$ Presented individually and in-person on campus. Topics derived from Year 1 TC notes.

${ }^{2}$ Presentations and scripts submitted to the instructor. Topics self-selected by each triad.

${ }^{3}$ Presented in triads remotely, online via Zoom. Topics self-selected by each triad.

The one big idea that was consistent throughout the three years was "building relationships," which represents Standard 1 (i.e., care for students) from the Professional Standards for British Columbia (BC) Educators (2019). Themes of differentiation, holistic assessment, and inquiry projects reflect Standard 5 (i.e., capacity to teach); and making learning accessible, motivation, and purposeful play highlight Standard 3 (i.e., student growth and development). The big ideas self-identified by TCs as individuals or triads at the Celebration of Learning revealed what they valued, what they have learned, and what best reflected their development of professional identity. 
Furthermore, the e-Portfolio and Celebration of Learning provided TCs an opportunity to demonstrate the professional standards digitally as individuals and collectively as triads or cohorts, that is, Standard 2 (professionalism), Standard 7 (professional learning), and Standard 8 (contributing to the profession). Community and collegiality were also evident. For example, in 2020 , the secondary cohort was relatively small, and they wanted to present together. They worked together for 2-years and demonstrated their agency to ask for what they wanted. The "septad" presented as one group for 20 minutes during the Celebration of Learning. e-Portfolios and Celebration of Learning provided a platform for TCs to share, collaborate, and celebrate their learning and achievements together. The use of e-Portfolios during final practicum was observed to help TCs to sense make, reflect, and make connections between each other, theory, and practice.

\section{Willingness to Share}

The third theme identified was the willingness of TCs to share e-Portfolio content and learning with others. Aside from presenting a few big ideas from their e-Portfolio during the Celebration of Learning, TCs willingly shared their e-Portfolio, voluntarily or on request, in the following ways:

- Using the About Me page to introduce themselves to school principals before practicum

- Presenting at WestCAST and using parts of their e-Portfolios in the PowerPoint

- Participating on Twitter and sharing links to their e-Portfolio in their bio or tweet

- Setting their e-Portfolio privacy settings as public and websites as searchable online

- Sharing their e-Portfolio links with course instructors for exemplars and course syllabus

- Giving permission to research faculty to share e-Portfolios at conference presentations

- Submitting e-Portfolio links as part of job applications, certification, or interviews

Sharing is a form of contribution to the profession (Standard 8). By extending the use of ePortfolios into final practicum, TCs were able to synthesize and summarize their teaching and learning experiences. TCs expressed pride in their accomplishments in the TEP and ePortfolios. TCs did not hesitate to say yes to sharing their e-Portfolios with other TCs, faculty, and others who were learning more about e-Portfolios and their use and potential in teacher education. TCs were also vulnerable and personal in their blog posts as part of their willingness to share. Some made connections with their struggles, new learning, and reflections. Others shared stories about their cultural heritage, family, or aspects of their personal life. Some TCs shared lesson plans, assignments, and coursework in their e-Portfolios, while others continue to use their e-Portfolios as practicing teachers to critically reflect or communicate with students and parents.

Learning was made visible using e-Portfolios. Another place where TCs were willing to share their teaching and learning experiences was with Twitter and microblogging. Although not all TCs participated on Twitter, TCs who chose to engage shared what was happening in their classroom, reflected on their teaching and learning, and expressed moments of gratitude. Some TCs participated on \#BCEdChat, an edu-chat on Twitter, as part of their professional learning or made connections with other BC educators or educators with a common interest. TCs shared 
their reflections, ideas about teaching and learning, and practicum updates on Twitter. Some TCs showed pictures of doing math in the snow, some had images of student work, while others shared photos with their triad at school visits or observations. All photos were FIPPA compliant. TCs also posted lesson plan ideas online, added their e-Portfolio link in their Twitter bio, noted participation in leadership roles such as coaching the volleyball team or leading the GSA club, or revealed special moments worth celebrating like getting their first teaching job.

\section{Conclusions}

Through this program evaluation, the initiative to extend the use of e-Portfolios into the final practicum at this teacher education program (TEP) was considered a worthwhile endeavour because teacher candidates (TCs) were able to maintain an e-Portfolio with artefacts that demonstrated their understanding of the professional standards and e-Portfolios were personalized to reflect who they were as learners and educators. TCs found appropriate artefacts from practicum and coursework and composed additional webpages that introduced themselves, highlighted their understanding of BC's Curriculum, and articulated any additional skills, values, competencies, or work experience to create a digital narrative of their professional identity. The e-Portfolio served both summative and formative purposes by providing a space for TCs to reflect and sense-make about theory and practice using a blog, but also choose artefacts and write rationales that represented their professional identity.

The e-Portfolio was used by TCs to make tacit moments and understandings more visible. It provided a vehicle for TCs to develop the Core Competencies, such as communication, reflective thinking, and positive personal identity, as described in BC's Curriculum. Furthermore, TCs were engaged in the First Peoples Principles of Learning (FNESC, 2008) as learners and reflective practitioners who reflect in and on practice (Schon, 1984). Learning was experiential, holistic, and embedded in memory, history, and story (FNESC, 2008). They explored their identities and recognized that "some knowledge is sacred and only shared with permission and/or in certain situations" (Chrona, 2014, title). They composed their digital narrative with the understanding of FIPPA, digital citizenship, and their digital footprint. Their actions online reflected what was expected of them and from them based on the Professional Standards for British Columbia Educators (2019). TCs were learning the professional standards and digital literacy experientially, learning by doing, and self-assessing each action or thought to inform the next (Earl, 2003; Kolb, 1984).

The e-Portfolio was used for reflection and assessment as learning (Earl, 2003) to provide ongoing formative feedback to the end of the program. The Celebration of Learning and completed e-Portfolio were summative, but the opportunities to collaborate with others, reflect on teaching, and find artefacts that represent the professional standards and who they are as educators (Palmer, 1989) were formative. Assessment as Learning (Earl, 2003) helped TCs to think about their thinking (and doing) and to develop their metacognitive skills as reflective practitioners. The ability to choose artefacts, design a website, and personalize content provided TCs with a sense of agency and pride. TCs shifted from a mindset of studenting (Liljedahl \& Allan, 2013) to one of learning and ownership. The use of e-Portfolios revealed professional qualities of TCs, such as agency, sense of community, and teacher efficacy, within the e-Portfolios, but also from the doing of e-Portfolios. They overcame extraordinary challenges during the implementation but remained professional, diligent, and on-task to effectively demonstrate their learning. 
In the end, engaging in e-Portfolios during final their practicum was a humanizing endeavour. As a whole, the e-Portfolios were personalized and unique even though some TCs started with a template. The self-selected big ideas presented at the Celebration of Learning based on their ePortfolios, such as building relationships, experiential learning, and differentiation, captured TC learning in the TEP from practicum, and reflected parts of TCs professional identity. Although not part of this investigation, the implementation of the other two initiatives to improve the practicum experience (i.e., triads and the single point rubric) may have complemented or enhanced what was observed and produced in the e-Portfolios in terms of self-assessment and understanding of the professional standards. TCs created a digital narrative of their teaching and learning using e-Portfolios (and Twitter) that reflected the professional standards and aspects of their professional identity. As a whole, TCs were vulnerable, willing to share and contribute, and made their learning and pedagogical stance visible to others. The extended use of e-Portfolios during final practicum was viable, but our next question is, can it be used throughout the program?

\section{Next Steps}

The next step towards action (and future program evaluation) is to design and implement a new course focused on reflective practice and e-Portfolios in the redesigned teacher education program (TEP) at this university. This course would be "cross cutting" throughout the TEP, meaning that this three-credit course, called EDUC 405, would replace EDUC 431 and continue throughout the four terms of the program. The redesigned program is intended to be a continuous 16-month program instead of a two-year program, and e-Portfolios would be primarily used for critical reflection, documentation, and demonstration of the professional standards. Teacher candidates (TCs) would be able to make visible their professional growth and identity formation over the entire program and be inclusive to other coursework and practicum. Although EDUC 405 would weave through and into other courses in the program, it would be expected that TCs would attempt to weave theory and practice together within their ePortfolios.

Student agency, student choice, and personalization would be essential outcomes for this new course in addition to making connections to BC's Curriculum, First Peoples Principles of Learning, and the Core Competencies to develop a reflective practice and one's professional identity. The following is a list of recommendations for EDUC 405 based on what was learned over the last three years from the e-Portfolio initiative and program evaluation:

- Use open-sourced WordPress from OpenETC (which is FIPPA compliant)

- Introduce e-Portfolios with a template which includes the minimum number of pages

- Choose artefacts and exemplars from practicum experiences and coursework

- Add additional pages that highlight personal competencies, strengths, or interests

- Maintain a blog for ongoing critical reflection and opportunities to sense make

- Encourage TCs to incorporate different types of media or applications

- Find opportunities for triads to collaborate, brainstorm, and provide peer feedback

- Include Twitter as part of the reflective practice and e-portfolio (optional use) 
- Conclude the program with a Celebration of Learning (and refer to e-Portfolios)

- Design the Celebration of Learning to be participatory and formative feedback

EDUC 405 would be implemented in the Fall term and conclude in the following Fall term.

Final Reflections

The program evaluation of extending the use of e-Portfolios into final practicum in this two-year teacher education program (TEP) was determined to be viable such that teacher candidates were able to maintain an e-Portfolio during final practicum, find artefacts that would best reflect their practice and professional standards, and share ideas during the Celebration of Learning and beyond. In doing so, TCs were able to develop their professional identity and reflective practice as new K-12 educators, make connections between theory and practice, and curate a digital narrative of who they are as a learner and educator as they deepened their understanding of the professional standards through practice. The e-Portfolio provided a digital platform for ongoing formative assessment during and after final practicum and served as a vehicle for reflection, sense-making, and self-assessment. E-Portfolios were personalized, and learning was made visible and public. The implementation revealed professional qualities of teacher candidates and they were in turn able to practice some of the professional standards and experience parts of BC's Curriculum. e-Portfolios during final practicum humanized the learning experience as it created space and time for teacher candidates to pause, reflect, and celebrate. The potential of using e-Portfolios throughout the teacher education program to develop a reflective practice through inquiry is plausible, but it may also help with creating more cohesion and coherence between coursework, practicum, the professional standards, and one's professional identity.

\section{Author's Contributions}

The author confirms sole responsibility for the following: program evaluation conception and design, collection of information, interpretation of information, and manuscript preparation.

\section{Open Researcher and Contributor Identifier (ORCID)}

Christine Ho Younghusband (D) https://orcid.org/0000-0002-0804-3537

\section{Acknowledgements}

The Open Educational Technology Collective (OpenETC) should be acknowledged for their contributions in supporting the innovative portfolio system used in this design.

\section{Ethics Statement}

Ethics review was not applicable because the inquiry was about evaluating and improving the program.

\section{Conflict of Interest}

The author does not declare any conflict of interest. 


\section{Data Availability Statement}

Data sharing is not applicable to this article as no new data were created or analyzed in this program evaluation.

\section{References}

BC Ministry of Education. (1989). Statement of education policy order (Mandate for the school system). https://www2.gov.bc.ca/assets/gov/education/administration/legislationpolicy/legislation/schoollaw/d/oic 128089.pdf

BC Teachers' Council. (2019). Professional standards for BC educators. https://www2.gov.bc.ca/assets/gov/education/kindergarten-to-grade-12/teach/teacherregulation/standards-for-educators/edu standards.pdf

Boulton, H. (2014). ePortfolios beyond pre-service teacher education: A new dawn? European Journal of Teacher Education, 37(3), 374-389. https://doi.org/10.1080/02619768.2013.870994

Chrona, J-A. L. (2014). Learning involves recognizing that some knowledge is sacred and only shared with permission and/or in certain situations. First Peoples Principles of Learning [Blog]. https://firstpeoplesprinciplesoflearning.wordpress.com/learning-involvesrecognizing-that-some-knowledge-is-sacred-and-only-shared-with-permission-andor-incertain-situations/

Earl, L. M. (2003). Assessment as learning using classroom assessment to maximize student learning. Corwin Press.

Eliot, M., \& Turns, J. (2011). Constructing professional portfolios: Sense-making and professional identity development for engineering undergraduates. Journal of Engineering Education, 100(4), 630-654. https://doi.org/10.1002/j.21689830.2011.tb00030.x

First Nations Education Steering Committee. (2008). First Peoples principles of learning. http://www.fnesc.ca/wp/wp-content/uploads/2015/09/PUB-LFP-POSTER-Principles-ofLearning-First-Peoples-poster-11x17.pdf

Friesen, M., \& Besley, S. (2013). Teacher identity development in the first year of teacher education: A developmental and social psychological perspective. Teaching and Teacher Education, 36(2013), 23-32. http://dx.doi.org/10.1016/j.tate.2013.06.005

Granberg, C. (2010). E-Portfolios in teacher education 2002-2009: the social construction of discourse, design and dissemination. European Journal of Teacher Education, 33(3), 309-322. https://doi.org/10.1080/02619761003767882

Hinchey. P.H. (2008). Action research. Peter Lang Publishing, Inc.

Izadinia, M. (2013). A review of research on student teachers' professional identity. British Education Research Journal, 39(4), 694-713. http://dx.doi.org/10.1080/01411926.2012.679614

Kaser, L., \& Halbert, J. (2017). The spiral playbook: Leading with an inquiring mindset in school systems and schools. C21 Canada. http://c21 canada.org/wpcontent/uploads/2016/10/Spiral-Playbook.pdf

Kitchenham, A. (2008). E-portfolios in teacher education: The UNBC experience. Collected Essays on Learning and Teaching, 1(2008), 142-148. https://doi.org/10.22329/celt.v1i0.3194 
Koehn, D., \& Younghusband, C. (2019, February 20). Side-by-side learning: Teacher candidates triads transforming practice through peer assessment during field experience [Conference presentation]. WestCAST 2019 Conference. Calgary, AB. https://westcast2019.sched.com/event/KS3T/e22-side-by-side-learning-teachercandidates-transforming-practice-through-peer-assessment-during-field-experience

Kolb, D. (1984). Experiential learning: Experience as the source of learning and development. Prentice Hall. https://pdfs.semanticscholar.org/f6ec/20a7a3150822140be7466353d0de572cc4bb.pdf

Liljedahl, P., \& Allan, D. (2013). Studenting: The case of homework. Proceedings of the ThirtyFifth Annual Meeting of the North American Chapter of the International Group for the Psychology of Mathematics Education, 489-492. https://www.pmena.org/pmenaproceedings/PMENA\%2035\%202013\%20Proceedings.pd $\underline{f}$

Maclntyre, A. (1981). After virtue: A study of moral theory. Notre Dame Press.

Maharsi, I. (2019). Pre-service teachers' reflective practices through teaching practicum eportfolios. Proceedings of the Fifth International Conference on Education and Training Technologies, 125-129. https://dl.acm.org/doi/10.1145/3337682.3337706

Oakley, G., Pegrum, M., \& Johnston, S. (2014). Introducing e-portfolios to pre-service teachers as tools for reflection and growth: Lessons learnt. Asia-Pacific Journal of Teacher Education, 42(1), 36-50. https://doi.org/10.1080/1359866X.2013.854860

Palmer, P. (1989). The courage to teach: Exploring the inner landscape of a teacher's life. Jossey-Bass.

Paul, C., \& Scholefeld, A. (2009, September 22). E-Portfolios for teacher candidates. The Centre for Teaching, Learning and Technology: University of British Columbia. https://ctlt.ubc.ca/2009/09/22/e-portfolios-for-teacher-candidates/

Province of British Columbia. (2021). BC's curriculum: Curriculum overview. https://curriculum.gov.bc.ca/curriculum/overview

Rowe, J. (2012, March). Assessment as learning. ETEC 510. The Centre for Teaching, Learning and Technology: University of British Columbia. http://etec.ctlt.ubc.ca/510wiki/Assessment as Learning

Schon, D. A. (1984). The reflective practitioner: How professionals think in action. Basic Books.

Stenberg, K., Rajala, A., \& Hilppo, J. (2016). Fostering theory-practice reflections in teaching practicums. Asia-Pacific Journal of Teacher Education, 44(5), 470-485. http://dx.doi.org/10.1080/1359866X.2015.1136406

Stolz, S. (2020). New pathways to the profession and teacher identity development. Teacher Education Quarterly, 47(2), 183-184. https://files.eric.ed.gov/fulltext/EJ1249341.pdf

Truth and Reconciliation Commission of Canada, United Nations., National Centre for Truth and Reconciliation., Truth and Reconciliation Commission of Canada., Truth and Reconciliation Commission of Canada., \& United Nations. (2015). Truth \& reconciliation: Calls to action. https://www2.gov.bc.ca/assets/gov/british-columbians-ourgovernments/indigenous-people/aboriginal-peoplesdocuments/calls to action english2.pdf 